\title{
Students' experiences of collaboration during and after an interprofessional training ward course: a mixed methods study
}

\author{
Hanna Lachmann ${ }^{1}$, Sari Ponzer1, Unn-Britt Johansson ${ }^{3}$, Klas Karlgren ${ }^{4}$, Bjöörn Fossum² \\ ${ }^{1}$ Karolinska Institutet, Department of Clinical Science and Education, Södersjukhuset, Sweden \\ ${ }^{2}$ Sophiahemmet University, Stockholm, Sweden \\ ${ }^{3}$ Karolinska Institutet, Department of Clinical Sciences, Danderyd Hospital, Division of Medicine, Sweden \\ ${ }^{4}$ Karolinska Institutet, Department of Learning, Informatics, Management and Ethics, Sweden \\ Correspondence: Hanna Lachmann, Karolinska Institutet, Department of Clinical, Science and Education, Södersjukhuset, \\ SE-118 83 Stockholm, Sweden. E-mail: hanna.lachmann@ki.se
}

Accepted: August 03, 2013

\begin{abstract}
Objectives: The objective of this study was to obtain a deeper understanding of how students experience and perceive interprofessional collaboration connected to their learning activities during and after an interprofessional clinical course.

Methods: A sample of 15 healthcare students participating on a two-week interprofessional clinical course was used. A mixed method approach was used for data collection. The students' perceptions were gathered several times a day via mobile phones by using the Contextual Activity Sampling System (CASS) and they were also interviewed after the course.

Results: The data revealed an interesting discrepancy between the students' learning experiences reported during the course compared to their perceptions after the course. The students were generally more critical during the course, i.e., they tended to report things that did not work well. In
\end{abstract}

the post-course interviews, the students reported that difficulties had been solved during the course. The students emphasized also the importance of structure, interaction, and insights into one's own and other professions' tasks as a base for fruitful interprofessional collaboration. Furthermore, they underlined the benefits of interprofessional team learning with opportunities to contribute to and to acquire new knowledge.

Conclusions: The CASS methodology provides possibilities to identify students' and student teams' needs of support to reach the intended learning outcomes of a specific course. Our results might be useful when developing clinical education with a special focus on supporting students in their collaborative practices.

Keywords: Interprofessional clinical education, interprofessional collaboration, mixed methods, students' experiences of interprofessional collaboration, trialogical learning

\section{Introduction}

To promote interprofessional collaboration, knowledge creation and learning are important goals for the clinical education of all healthcare professionals. Although it is well known that there are many benefits of interprofessional collaboration for patient care, there is still a need to better understand and assess students' interprofessional collaboration experiences and learning in order to develop and renew clinical educational models. ${ }^{1,2}$ Previous attempts to describe the interactional factors during interprofessional collaboration in clinical settings have often encountered methodological challenges. Those challenges may have affected the acquired data due to recall or social desirability biases. ${ }^{3}$ The CASS methodology has been shown in previous studies to provide the means to investigate the way in which students pay attention to activities that they are engaged in. It is characterized by frequent and systematic data gathering over time which makes it possible to capture students' perceptions and follow their development during learning activities. ${ }^{4-7}$ Lave and Wenger ${ }^{8}$ have described learning as an everyday activity with an emphasis on the idea that much of what is learned is specific to the situation in which it is learned. They also emphasized that learning is developed by 
participation in communities of practice. Furthermore, work-based learning has been recognized as being fundamental for undergraduate clinical medical education and also that learning is more effective when done in dialogue with other students. ${ }^{9,10}$ Lewin and Reeves ${ }^{11}$ emphasize the importance of enhancing collaboration with informal communication and teamwork on the hospital ward between health professionals. Walton and Steiner ${ }^{12}$ have pointed out the value of students applying knowledge and skills in worked-based learning situations. Interprofessional clinical educations facilitates engagement for knowledge creation activities, so-called trialogical learning. ${ }^{7}$ Such opportunities are offered, for example, on interprofessional clinical training wards where students can also get their questions answered, be involved in discussions, and start to socialize in the community of clinical practice. ${ }^{13,14}$

The interprofessional training wards were developed to provide teams of healthcare students with opportunities to practice clinical skills and apply their theoretical knowledge in an interprofessional learning environment. ${ }^{15,16}$ The intended learning outcomes for an interprofessional clinical course include learning to work together in a suitable clinical practice, to enhance one's understanding of other students' professions, to develop one's own professional role, and to function as a team member. ${ }^{16,17}$ The World Health Organisation ${ }^{18}$ has acknowledged that there is sufficient evidence indicating that interprofessional education, e.g., in clinical settings, enables effective collaborative practice and promotes the quality of patient care. In previous studies it has been stated that interprofessional education is a prerequisite for students to understand the complexity of professional practice, patient care and also as a key issue for curriculum developers in healthcare sciences. ${ }^{19}$ Lidskog et al. ${ }^{20}$ have also shown that collaboration with fellow students is valuable and enjoyable. However, there is still a need to better understand the complexity of students' individual experiences in collaboration, team learning, how these connect to each other and if they vary during an interprofessional clinical course.

The objective of this study was to obtain a deeper understanding of how students experience and perceive interprofessional collaboration connected to their learning activities during and after an interprofessional clinical course.

\section{Methods}

\section{Design of the study}

To create a synergistic understanding of team collaboration during interprofessional clinical courses, a mixed methods approach was chosen. ${ }^{21}$ Quantitative and qualitative data were collected via the CASS during interprofessional courses and qualitative data via semi-structured interviews on the last day of each course. The CASS methodology, inspired by the Experience Sampling Method (ESM) ${ }^{22}$ was designed with the aim to provide researchers and users with means to collect frequent and systematic data about students' perceptions of learning activities while they occur. The CASS methodology as such uses a mixed methods approach that makes it possible to collect both qualitative (free text comments) and quantitative data (ratings on predefined scales). This approach has been shown to be useful for interprofessional education in clinical settings. ${ }^{6,7}$ The interviews conducted on the last day of each interprofessional course were aimed at giving a deeper understanding of the students' experiences and also at further exploration of the students' perceptions of how the team collaboration had worked.

\section{Participants and context of the study}

This study took place in 2009 and was part of a larger project conducted at a Swedish teaching hospital on an interprofessional training ward, an orthopedic ward with nine beds. The two-week interprofessional course was mandatory for undergraduate students from medical, nursing, occupational therapy, and physiotherapy programs. A total of 15-18 students, divided into three teams, participated during each course. The course started with a team-building day aimed at letting the students get to know their team members (5-6 students) before the first day on the ward. ${ }^{17}$ Two of the three student teams from six courses were randomly assigned to be potential participants in this study and the third team was assigned to a control group (data not used in this study). ${ }^{6}$ A total of 63 students were eligible and were approached, $81 \%$ of whom $(\mathrm{n}=51)$ consented to participate. The students who completed at least 15 CASS questionnaires were included in this study $(\mathrm{n}=15)$.

\section{Procedure for using CASS and the CASS questionnaire}

The students were provided with mobile phones and given short instructions (oral and written) on how to use CASS. They retrieved the questionnaires by connecting to a database server and using a specific application on their mobile phones. ${ }^{6}$ The students were asked to answer three CASS questionnaires each study day on the ward, a total of 18-24 questionnaires depending on how many study days (range 6-8 days) they were on the ward. The vibration and sound signals of the mobile phones were used to remind the students to relate their replies to the on-going learning activity that they were engaged in and they were asked to answer as soon as possible with the particular activity in mind. The questionnaires took about three to five minutes to complete. The students were asked to describe what type of activity they were engaged in, to report where they were and if they were collaborating with someone, e.g. "Are you collaborating with someone right now? Answer yes or no. If yes, with whom?" The students were also asked to rate on a Likert scale (1-7, with 7 indicating full agreement) their perceptions regarding how well the team collaboration worked out. 
And they were also encouraged to write free text comments in case they wanted to report anything in particular or suggest how the team collaboration could be improved.

The free text comments collected via CASS were related to the post-course interview data in cases where data were available via both methods. This with the purpose of exploring the students' experiences of collaboration, finding similarities and differences in data collected during courses in contrast to when recalled by the respondents after the courses.

\section{Statistical procedures}

Since all of the included 15 students did not respond to all CASS questions, a missing data analysis was performed. Data percentages were calculated for each question and each student. Thereafter, the students' standardized scores (Z-scores) for rated perceptions of collaboration were calculated in order to determine if the rated scores were above or below the individual averages. This was done to position an individual rating, based on the variation in students' perceptions about collaboration in relation to course activities and to the day of the course. To assess whether there were any significant correlations between the investigated perceptions and day on the course or different activities, a $\mathrm{p}$ value of $<0.05$ was regarded as statistically significant. The Statistical Package for Social Sciences (SPSS version 19) was used for the data analysis.

\section{Interviews after the courses}

During the last day of each course, semi-structured interviews were conducted (by the first author, HL) with each participant. The interviews lasted 13-40 minutes (average 26 minutes) and were tape-recorded, to which none of the students had any objections. The following five interview questions were analyzed for the purpose of this study:

1. How do you think the team collaboration worked with the students of the other professions?

2. Have there been any difficulties or challenges in the team collaboration?

3. How do you think the communication worked in your team?

4. What do you think you have learned about interprofessional collaboration during this interprofessional course?

5. What has changed in your team's collaboration during the course?

\section{Analysis of the qualitative data}

Free text comments reported via CASS and data gathered during the post-course interviews were analyzed by means of content analysis with the purpose of describing similarities and differences and to identify patterns. ${ }^{23,24}$

With the intention of detecting the students' experiences concerning their team collaboration, all authors read the free text comments reported via CASS independently and thereafter discussed the findings within the research group. The first author (HL) listened to the 15 interviews several times to obtain a naïve understanding of the entire material. Thereafter the interviews were transcribed verbatim. When the interviews had been transcribed, the first author (HL) and one of the co-authors (BF) read each interview one by one several times, open-mindedly going through them word for word. The transcribed interviews were entered into the NVivo 9 software for the purpose of efficiently organizing and managing the data before starting the coding process. ${ }^{25}$ In order to distinguish between what was essential and unessential, e.g., repetition of person-specific expressions, names, and laughter were sorted out. ${ }^{23,24}$

Furthermore, what Hsieh and Shannon ${ }^{26}$ have labeled a qualitative conventional content analysis was performed to get a deeper understanding of how the students perceived interprofessional collaboration in relation to their learning activities during and after an interprofessional clinical course. A conventional content analysis signifies that coding categories are derived directly and inductively from the collected data.

The meanings of the CASS free text comments and the transcribed interviews that were extracted and condensed into meaning units were labeled as categories. The categories should be regarded as various conceptions of a phenomenon appearing in different situations and related to the whole group of students rather than to individual respondents. The categories were used to organize and group the phenomenon into meaningful clusters that constitute the manifest content. The aim of the process of creating categories labeled with content-characteristic words was to increase understanding and describe the phenomenon based on the students' perspectives pertaining to collaboration during their interprofessional clinical education. This process was repeated back and forth between the original text and the condensed meaning units, and categories to achieve a self-critical and open-minded approach for alternative interpretations. The latent content (underlying meaning) was formulated as a theme. To ensure trustworthiness and to improve the depth and breadth of the data, the meaning units, condensed meaning unit, categories, and choice of a theme were discussed within the research group until a consensus was reached. The credibility is assessed as being high, considering that the students describe experiences and perceptions of their own activities during and after the interprofessional course..$^{23,24}$

\section{Ethical considerations}

This study was approved by the Regional Ethical Review Board, Karolinska Institutet, Stockholm, Sweden. The students were informed individually, orally and in writing, about the study design, that the participation was voluntary, and that the results would not have any impact on their grades and would only be used for research purposes. 


\section{Results}

\section{Participants and response rate}

The 15 students included in this study were aged from 22 to 44 years and responded to 15 to 23 questionnaires each during their two-week interprofessional clinical course. In total, 318 CASS questionnaires were available for them to respond to, out of which 277 (87\%) were completed (Table 1). The main reason for the students not responding was related to technical difficulties with the server and weak signals from the mobile operator. ${ }^{6}$ All students were interviewed during the last day of their course.

Table 1. Participants' characteristics, the number and percentage of answered questionnaires by student category

\begin{tabular}{|c|c|c|c|c|c|c|c|c|c|c|}
\hline \multirow[t]{2}{*}{ Participants } & \multicolumn{2}{|c|}{$\begin{array}{l}\text { Medical } \\
\text { students }\end{array}$} & \multicolumn{2}{|c|}{$\begin{array}{l}\text { Nurse } \\
\text { students }\end{array}$} & \multicolumn{2}{|c|}{$\begin{array}{l}\text { Occupa- } \\
\text { tional } \\
\text { therapist } \\
\text { students }\end{array}$} & \multicolumn{2}{|c|}{$\begin{array}{l}\text { Physio- } \\
\text { therapist } \\
\text { students }\end{array}$} & \multicolumn{2}{|c|}{$\begin{array}{c}\text { All } \\
\text { included } \\
\text { students }\end{array}$} \\
\hline & $n$ & $\%$ & $n$ & $\%$ & $\mathrm{n}$ & $\%$ & $n$ & $\%$ & $n$ & $\%$ \\
\hline Total & 6 & 40 & 6 & 40 & 1 & 7 & 2 & 13 & 15 & 100 \\
\hline Male $\hat{\jmath}$ & 4 & & 0 & & 0 & & 1 & & 5 & 33 \\
\hline Female $q$ & 2 & & 6 & & 1 & & 1 & & 10 & 67 \\
\hline
\end{tabular}

Answered CASS questionnaires

$\begin{array}{lcccccccccc}\text { Total } & 101 & 36 & 111 & 40 & 23 & 8 & 42 & 16 & 277 & 100 \\ \text { Male } \delta & 70 & & 0 & & 0 & & 21 & & 91 & \\ \text { Female } q & 31 & & 111 & & 23 & & 21 & & 186 & \end{array}$

\section{Quantitative CASS data}

In 146 (53\%) of the 277 returned questionnaires, the students had rated their perceptions on a Likert scale (1- 7, with 7 indicating full agreement) concerning how well the team collaboration had worked out. There were no correlations or significant differences in responses between how well the collaboration was perceived and day of the interprofessional course. The students appreciated it when the team worked collaboratively with tasks connected to patient care and, accordingly, scored these activities high; the mean rating was 6.37 , $(\mathrm{SD}=0.91$, range $3-7)$. However, when the student team discussed a patient during a ward round and reported about the actual situation on the ward to another student on the team or had reflections after their study day, they did not consider these activities as collaboration and consequently did not choose to rate how well the collaboration had worked.

\section{Qualitative CASS data versus interview data}

The experienced aspects affecting interprofessional collaboration resulted in a theme: Structure, interaction and insights facilitate students' clinical interprofessional collaboration. The theme emerged from six categories developed from both CASS data and interview data, but the postcourse interviews revealed new data that did not relate to the CASS free-text comments (Table 2).

These categories are described below with quotes illustrating the variation of reported perceptions as noted in the CASS free-text comments and/or as described by the students during the post-course interviews.

\section{Allocation of tasks}

The category Allocation of tasks describes the students' perceptions and understanding of in what way activities were allocated and carried out. One nursing student (female, age 37 years) wrote the following comment via CASS:

"No structure. Disturbing"

In the post-course interview the same student described the allocation of tasks as natural and that everyone knew what to do even if the team did not always manage do finish all tasks. She said:

\section{"Tasks were allocated in a natural way. There was no doubt who was supposed to do what." \\ "Not everything was always completed; some students could not find the right level for what should be done."}

A physiotherapy student (male, age 22 years) reported the same type of perception and gave a suggestion via CASS:

$$
\begin{aligned}
& \text { "Working by myself." } \\
& \text { "Allocate the work." }
\end{aligned}
$$

After the course the same student described the difficulties but also confirmed that the team had solved the problems during their daily activities with the support of the tutors and that the roles and responsibilities had become clear. $\mathrm{He}$ said:

$$
\begin{aligned}
& \text { “... it didn't go as planned, which tested our team, but I feel that } \\
& \text { we solved the tasks anyway." } \\
& \text { "... each and every one has had responsibilities. From the start } \\
& \text { it was clear that I had the responsibility of helping patients to } \\
& \text { become mobile and to exercise and the nursing students had } \\
& \text { their own responsibilities. I feel that everyone has taken respon- } \\
& \text { sibility for their own tasks... of course the tutors have supported } \\
& \text { and directed us, and that is very good and as it should be; oth- } \\
& \text { erwise, it would had been difficult if we had not known this." }
\end{aligned}
$$

Most of the comments via CASS were about a lack of structure and unclear roles, while in the post-course interviews, the students underlined that even if there had been difficulties, the team had solved the problems and completed the tasks.

\section{Communication}

The Communication category was perceived as important and valuable. The students reported via CASS that they experienced problems with the team communication and that they perceived the communication to be more informative rather than a dialogue during on-going course activities, but in the interviews they said that it had become easier to communicate over time. A physiotherapy student (male, age 22 years) called for more communication in his CASS responses and also commented on the progress during the on-going course:

\section{"Increased communication." \\ “Getting better over time."}


In the post-course interview the same physiotherapy student reflected and said:

“... one should dare to ask for help when one doesn't understand... I haven't before, and I have avoided asking a physician mainly because I have thought that he had no interest in my tasks... but now I have dared to ask more often ...I don't think we have had (on the student team) any problems in talking with each other about any specific problem or such..."

One nursing student (female, age 37 years) reported via CASS a lack of communication during on-going activities and also gave a suggestion:

"More information than communication."

"Let one person speak at a time."

The same student did not recall any communication problem in the post-course interview but commented on her own role on the team:

".... everybody wants to be acknowledged and think that his or her area is the most important. I have learned that I can back off when needed... otherwise, I'm usually the one who says how things should be, but I have not done so this time..."

The students emphasized both via CASS and via the interviews the importance of structure for well-functioning communication and the enhancement of team activities. They also expressed their satisfaction with having managed to plan their daily tasks as a team and having learned to listen to each other.

\section{Team resources for interprofessional learning}

Team resources for interprofessional learning were the category that explained the students' perception of being part of a real clinical context. The different types and levels of knowledge that were available within the student team were perceived as being difficult, but also as a prerequisite for giving good patient care. One physiotherapy student (male, age 22 years) reported via CASS:

"It's necessary to have knowledge of the issues that are important to discuss during the ward round."

In the post-course interview the same student said:

"... (the team activities) have been on a good level, so nobody has been considered to be superior to the others and we have dared to ask..."

“...if I or someone else didn't understand something ... we have tried to help and teach each other about our special areas, and I feel that I've become less stressed and more competent ...."

One nurse student (female, age 23 years) reported via CASS:

“... I will get more experience."

In the post-course interview she stated:

\footnotetext{
"We became surer about each other and the group became close-knitted over time."

“... it has been easy to talk with medical and physiotherapy students. I didn't feel like I was asking stupid questions, which I
}

may have felt if talking to a physician who has been working for a long time ... everyone in the team supported each other."

The students appreciated the possibility of using each other's knowledge and perceived it as necessary, important, and pleasant that everybody contributed to the team and supported each other. The students' perceptions of belonging to an interprofessional team in a real clinical context enabled them to understand the importance of different areas of knowledge and enhanced their interactions when collaborating with one another.

\section{Participating}

Participating was used as the category to describe the students' stories about their acquired insights concerning aspects of being part of a healthcare team and also about their perceptions concerning assumed leadership within the interprofessional team. They said that the course was experienced as being valuable since it provided possibilities for understanding the importance of team collaboration in a real clinical context. One nursing student (female, age 22 years) said regarding the importance of team collaboration and also reflecting on the team development:

"The workflow is better if you collaborate because you avoid misunderstandings. In the beginning we were really focused on our own tasks I mean like this - this and that I really have to do today - but when, after two days or so, one got insight into this (system) - OK, I can't manage everything by myself - like, we have to help each other."

Sometimes the team collaboration was also perceived as being limiting. An occupational therapist student (female, age 44 years) reflected in the following way:

"... I felt like some (of the team members) were a little bit too fast in their doings compared to what I would have done, but I didn't want to say anything in front of the patient; in such cases I have waited..."

A medical student (male, age 30 years) described the team collaboration as enjoyable, pleasant, and valuable and said:

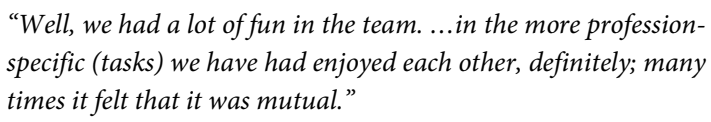

During the interviews it also appeared that medical students were assumed to have a leader role and were also perceived as team leaders by both the other students and themselves. A medical student, male, age 30 years, said:

\footnotetext{
"During the ward rounds it felt like the medical students had some kind of leader role, at handovers the nurses took up a little more space. But I kind of think that in many cases it became so that the medical students led the activities, in a way."
}

And a nursing student (male, age 23 years) said:

"The medical students have been kind of leaders." 
Table 2. An overview of the systematic qualitative data analysis coding scheme for the research question concerning students' perceptions of interprofessional collaboration connected with learning activities during (reported via CASS) and after a clinical IPE-course (collected by interviews)

\begin{tabular}{|c|c|c|c|}
\hline $\begin{array}{l}\text { Free text comments } \\
\text { reported via CASS }\end{array}$ & Condensed meaning unit emerged from the interviews & Code & Theme \\
\hline No structure. Disturbing. & $\begin{array}{l}\text { Tasks were allocated in a natural way. There was no doubt who was supposed to } \\
\text { do what. }\end{array}$ & Allocation of tasks & \multirow{2}{*}{ 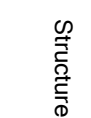 } \\
\hline Increased communication. & ... one should dare to ask for help when one doesn't understand. & \multirow[t]{3}{*}{ Communication } & \\
\hline Getting better over time. & & & $\underset{\overparen{D}}{\mathrm{D}}$ \\
\hline $\begin{array}{l}\text { More information than } \\
\text { communication. }\end{array}$ & $\begin{array}{l}\text {... everybody wants to be acknowledged and think that his or her area is the most } \\
\text { important. I have learned that I can back off when needed }\end{array}$ & & 号. \\
\hline $\begin{array}{l}\text { It's necessary to have } \\
\text { knowledge about the issues } \\
\text { that are important to discuss } \\
\text { during the ward round. }\end{array}$ & $\begin{array}{l}\text {... (the team activities) have been on a good level so nobody has been considered } \\
\text { to be superior to the others and we have dared to ask. We have tried to help and } \\
\text { teach each other about our special areas and I feel that l've become less } \\
\text { stressed and more competent. }\end{array}$ & \multirow[t]{2}{*}{$\begin{array}{l}\text { Team resources for } \\
\text { interprofessional learning }\end{array}$} & 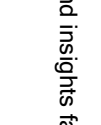 \\
\hline I will get more experience. & $\begin{array}{l}\text { We became surer about each other and the group became close-knitted over } \\
\text { time. I didn't feel like I was asking stupid questions. }\end{array}$ & & 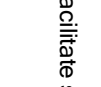 \\
\hline \multirow[t]{3}{*}{ b } & $\begin{array}{l}\text { The workflow is better if you collaborate because you avoid misunderstandings. } \\
\text { I can't manage everything by myself ... we have to help each other. }\end{array}$ & \multirow[t]{3}{*}{ Participating } & $\frac{\overrightarrow{0}}{\stackrel{0}{\vec{D}}}$ \\
\hline & The medical students have been kind of leaders. & & $\cong$ \\
\hline & $\begin{array}{l}\text { It feels like everybody expected that the medical students should have a minor } \\
\text { but not obvious leader role, but a little anyway. }\end{array}$ & & 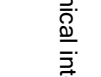 \\
\hline \multirow[t]{2}{*}{ b } & $\begin{array}{l}\text { I feel that everything fell into place and I understand now that all professions are } \\
\text { needed just as much. }\end{array}$ & \multirow[t]{2}{*}{ Patient safety } & $\frac{\mathrm{c}}{\mathrm{c}}$ \\
\hline & $\begin{array}{l}\text {... it is easier to give good care if you talk to each other and discuss different } \\
\text { issues with others. }\end{array}$ & & $\frac{\omega}{0}$ \\
\hline \multirow[t]{3}{*}{ b } & $\begin{array}{l}\text { I have also detected gap in my knowledge ... In the beginning it was all about } \\
\text { learning from the others, but as more days passed, I noticed that others could } \\
\text { also learn from me. }\end{array}$ & \multirow[t]{3}{*}{ Professional role } & 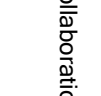 \\
\hline & $\begin{array}{l}\ldots . \text { it was very useful to get a more realistic picture of what to expect and what } \\
\text { others are expecting me to take responsibility for. }\end{array}$ & & \\
\hline & Now I understand my professional role on a ward. & & \\
\hline
\end{tabular}

${ }^{\mathrm{b}}$ No responses via CASS questionnaires during on-going clinical IPE-course

Another medical student (male, age 27 years) reflected:

"It feels like everybody expected that the medical students should have a minor but not obvious leader role, but a little anyway. Both us and the nursing students ... so that is probably also really how it was."

\section{Patient safety}

The category Patient safety describes the students' acquired understanding of the different professions' views on different perspectives concerning how to solve upcoming problems. An occupational therapy student (female, age 44 years) said:

"...it gives a feeling of security having them around, so you're not alone with patients but that there is always someone there seeing it from another perspective."

The team collaboration seemed to give a feeling of security for the students and also facilitated communication for improved patient care. One physiotherapy student (male, age 22 years) said:

"... since all (students) were continuously on the ward, you ran into each other all the time, so you say something about the patient and the other answers, so I think it (communication) has worked well. Somehow, I feel that everything fell into place and I understand now that all professions are needed just as much. If a (profession) is gone, it will make things difficult."

And a nurse student (female, age 23 years) said:

"... it is easier to give good care if you talk to each other and discuss different issues with one another."

The students also emphasized the value of collaborating on the team around the patient for good patient care.

One medical student (male, age 25 years) said:

"....after going around to all patients on the ward, I realized the benefit of bringing along a nurse or occupational therapist, that I perhaps should have asked them...wondering why I'm went by myself... it was good that there were more than one."

\section{Professional Role}

The category Professional Role describes the students' awareness of how one's own and the other team members' professional role became clearer during the course. The students' descriptions concerning identifying one's own professional role can be exemplified by a medical student's (male, age 36 years) reflection:

\footnotetext{
“... I guess I have found a little more of them ... we have found a few more roles..."
} 
How one's own trustworthiness increased was described in the interviews, giving an insight into the possibility of both contributing and acquiring knowledge during interprofessional collaboration. A nursing student (female, age 28 years) said:

\begin{abstract}
"... the longer I have been here (on the ward), the more I have developed my own knowledge of the patient and such like... but I have also detected gaps in my knowledge, like finding holes... but things have gotten better over time... concerning how I can contribute to the team. In the beginning it was all about learning from the others, but as more days passed, I noticed that others could also learn from me."
\end{abstract}

While different roles were clarified during the course, the students felt that it became easier to know how to support each other and how to allocate tasks. They increased their understanding for other professions' tasks, which instilled respect, as illustrated by a quotation from a medical student (male, age 30 years).

\begin{abstract}
“...you don't know, for example, if nurses are trained to listen to the heart or lungs, which I thought was part of their education, but it appears not to be... The same also applies to drugs, what nurses know about drugs and how they interact and so on, and why certain types of drugs are administered. For me, it was very useful to get a more realistic picture of what to expect and what others are expecting me to take responsibility for."
\end{abstract}

One physiotherapy student (male, age 22 years) told about how he understood his own responsibilities on a ward:

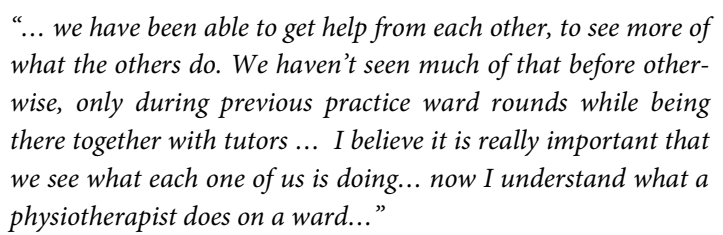

The students reflected during the interviews on their new insights into, for example, the importance of structure for fruitful participation in team activities. They also felt that the interactions with other students during the interprofessional course formed a basis for understanding the roles and tasks of the different professions. Furthermore, they said that during the interprofessional clinical course, their own professional role became clearer and that they experienced that their trustworthiness had increased.

\section{Discussion}

During an interprofessional clinical course students' perceptions of collaboration might vary over time, and also between individuals. Healthcare team members must acquire an understanding of the way in which the knowledge and skills of the other professionals can contribute in a given situation. Thus, as part of the learning process, the students need to be trained in, and acquire skills for, good collaboration. ${ }^{27}$ Interprofessional clinical practice in undergraduate programs supports this type of training and it is also possible that methods like CASS can help students to reflect on their daily interactions within the team and thereby increase their understanding of their own and other professionals' tasks and learning experiences on a ward.

The perceptions reported by the students concerning the collaboration activities during the course showed that they had acquired considerable knowledge concerning the value of structure during interprofessional interactions. They also emphasized the importance of their own and others' knowledge about different professional undertakings in order to carry out effective team activities. However, while still on the course, the students also reported via CASS that it was annoying that their team collaboration sometimes failed due to the lack of structure or poor communication within the student team. On the other hand, during interviews at the end of the course they cited the activities with other students during the course, as the most appreciated ones, something they had not experienced earlier during their education or been engaged in. A surprising finding was also that the students did not perceive some of the course activities that might be seen as typical team activity situations as being collaborative. Such activities were, for instance, when the student team discussed the patients on a ward round, reported about the situation on the ward to another student team, or were engaged in a reflection session on allocated time to discuss the events of the study day. This implies that these types of activities might have been regarded more as information transfer than as communication or collaboration within the team. According to Walton and Steinert ${ }^{12}$ the ward round is a powerful learning situation for team interactions and it should be ensured that teaching points are facilitated and that all team members are actively involved. The fact that the students in this study did not regard the ward round as a collaborative activity implies that more effort should be put on interaction and feedback in order to use the ward round as a team learning opportunity.

The most striking observation was that when the CASS data collected during the course was presented in relation to interview data, almost no overlap could be noted. The CASS data were generally more critical, i.e., the students tended to report things that did not work well, while in the interview data, most of the students reported that even if there had been difficulties, they were solved during the course. This was a somewhat unexpected finding. There are probably several reasons for these discrepancies. One explanation could be that the students reported their experiences via CASS when their memories were fresh, whereas these experiences may have been forgotten when the post-course interviews were conducted. The students also may have changed their mind when they found ways to handle the problems during the course or they just accepted the situation for the time being and did not consider the issues to be important enough to bring up at the end of the course. ${ }^{6}$ The main difference between the data collection methods is that the interviews at the end of the course 
encourage overall reflections, while the CASS data collected during the course may capture contextualized experiences. These methodological differences, also reflected in the results, imply that putting more emphesis on supporting individuals and dedicating more time for reflecting and discussing the daily interactions within the team would be beneficial for the development of interprofessional courses.

Even if the perceptions reported via CASS regarding how well the collaboration worked did not show any significant variation between the course days, it is likely that the students' activities worked out better toward the end of the course. Perhaps an additional question about the differences concerning how well the team collaboration worked out, compared with the day before, would have given another type of information and altered the outcome. It should also be noted that all students had participated in team-building training during their first day of the course aimed at providing them with the possibility of getting to know each other and starting the team-building process already before their first day on the ward. This activity is known to accelerate team collaboration ${ }^{15}$ but even so, our experience is that student teams need some days to find their ways of collaboration, which view is also partly supported by our interview data. In some situations the students experienced that they were to a great extent, only informed instead of being engaged in a two-way communication. This might be related to the fact that medical students were regarded as team leaders, both by themselves and by their fellow students. Despite the explicit goal of the course to emphasize interprofessional learning in a healthcare context, the traditional and hierarchical organization of work with the leadership focusing on the physician may be persistent. One reason could be related to the organizational framework, as previously described, ${ }^{28,29}$ which might not be ideal for the optimal use of the professionals' overlapping competences in future health care systems. Even so, the collaborative activities in the interprofessional teams seemed to encourage individual students to better understand, use, and share what they already knew. Understanding of one's own and others' professional roles is an acknowledged competency that provides richness, depth, and essence in interprofessional practice. ${ }^{30}$ In the interprofessional clinical environment, the students from different professions were able to become aware of the fact that they had valuable and important knowledge to contribute to the team, i.e., none of the team members knew "everything." The students became clearer about how the others expected them to contribute to the team; they identified their own knowledge gaps and became more familiar with the other professionals' knowledge, skills, and tasks. Hylin ${ }^{15}$ stressed that collaboration with other professions assumes an understanding of the roles, function, and specific skills of each profession. The student's in this study reported that they had acquired insights concerning each team member and noted their unique knowledge, frame of reference, and personality. These insights provide opportu- nities for knowledge creation and optimal experience, as described previously by Nonaka and Toyama ${ }^{31}$ and Paavola and Hakkarainen. ${ }^{32}$ In previous studies, Csikszentmihalyi and LeFevre ${ }^{33}$ and Fave and Massimini ${ }^{34}$ have called attention to the fact that optimal experiences create a positive circle of appreciation of the situation and that they are a prerequisite for long-term effects of individual development.

The students emphasized the value of a continuous dialogue during the study day to assure patient safety issues and appreciated the time given during the study days to reflect and discuss, and thereby solve, problems. They stressed the importance of good communication between the team members, as well as with the tutors. This finding is important, as reflected in previous work regarding patient safety which underlines the importance of providing possibilities for communication in order to prevent errors in clinical practice. ${ }^{35}$ Furthermore, it was interesting to note that patient safety aspects were not brought up by any of the students via CASS but was emphasized by several students during the post-course interviews. This might be due to the students being more focused on being a team member during their study days and therefore reported only on questions related to team collaboration rather than on issues concerning the care of the patients.

During the interviews the students described their beliefs regarding their ability to manage upcoming tasks instead of refraining from participation out of fear of not being able to manage the situation. The interprofessional clinical context was perceived and experienced as a safe and permissive environment with opportunities to ask student colleagues who are their equal and get questions answered, to practice in collaboration, and still take responsibility for the care of the patients on the ward. The students also reported on their experiences of belonging to an interprofessional student team where they helped each other and did not feel stupid when asking each other questions. Thus, interprofessional education in clinical settings encouraged students to share tasks and discuss problems within the team although the medical students were perceived as the ones who led the activities and the team in a way that several students expected and seemed to accept. To participate in an interprofessional clinical course for undergraduate students provides possibilities to acquire knowledge about how and when it is highly useful to collaborate or take advantage of other professions' competences.

The strength of this study was the use of methods that enabled identification of discrepancies in the data regarding students' perceptions of collaboration during and after the conducted course. Furthermore, by including qualitative and quantitative data, this study contributes to a deeper and broader understanding of how students perceive the interprofessional team collaboration connected with their learning activities. However, this study has some limitations that should be noted. Firstly, rather few students wrote free text comments via CASS and it is therefore possible that the 
noted comments did not reflect the opinions of all students. Secondly, due to technical difficulties it was not possible for the students to fill out all possible questionnaires. Thirdly, since the interviews were performed after the course it is possible that the students had forgotten details about activities performed during the course but on the other hand this type of risk for recall bias is one of the main reasons for using CASS. Thus, since the students described their experiences and perceptions of their own clinical practice on the ward during and after the interprofessional course, the credibility of the outcomes can be assessed to be rather high. The results of this study should therefore be transferable to other similar situations by virtue of a clear description of the methods and context.

\section{Conclusion}

Being a student on an interprofessional clinical ward seems to provide unique experiences for future team activities in healthcare. The students stressed that every member of the team contributed with their own knowledge and that good communication between the team members was needed for both patient safety and for feeling secure within the team. The results also showed that structure, interaction, and insight into one's own and others' professional tasks were important aspects that facilitate team collaboration. An important finding was the discrepancy between the students' perceptions reported by CASS and those revealed during the interviews and this needs to be explored in greater depth. CASS provides possibilities to discover how and when students or student teams may need more support to reach the outcomes of a specific course. Our results might also be useful when developing interprofessional clinical education and training with a special focus on how to better support students in their collaborative practice.

\section{Acknowledgements}

The authors wish to thank the students at Karolinska Institutet, Södersjukhuset, who participated in this study, the tutors working on the training ward as well as the Nokia Corporation for generously lending us telephones for this study. Financial support was provided through the $6^{\text {th }} \mathrm{EU}$ Framework Program for Research and Development; the Regional Agreement on Medical Training and Clinical Research (ALF) between the Stockholm County Council and Karolinska Institutet; Sophiahemmet University; and the Foundation for Medical Research at Sophiahemmet, Stockholm, Sweden.

\section{Conflict of Interest}

The authors declare that they have no conflict of interest.

\section{References}

1. Freeth D. Interprofessional education. In: Swanwick T, editor. Understanding Medical Education, Evidence, Theory and Practice. London: Wiley-Blackwell, 2010.
2. Thannhauser J, Russell-Mayhew S, Scott C. Measures of interprofessional education and collaboration. Journal of Interprofessional Care. 2010; 24(4): 336-349.

3. Reis HT, Gable SL. Event sampling and other methods for studying daily experience. In: Reis T, Judd CM, editors. Handbook of Research Methods in Social and Personality Psychology. New York: Cambridge University Press; 2000 .

4. Muukkonen H, Hakkarainen K, Kosonen K, Jalonen S, Heikkil A, Lonka $\mathrm{K}$, et al. Process-and context-sensitive research on academic knowledge practices: developing CASS-tools and methods. Proceedings of the 8th International Conference on Computer Supported Collaborative Learning; New Brunswick, New Jersey, USA. 1599699: International Society of the Learning Sciences; 2007.

5. Muukkonen $\mathrm{H}$, Inkinen $\mathrm{M}$, Kosonen $\mathrm{K}$, Hakkarainen $\mathrm{K}$, Vesikivi $\mathrm{P}$, Lachmann H, et al. Research on knowledge practices with the contextual activity sampling system. Proceedings of the 9th International Conference on Computer Supported Collaborative Learning - Volume 1; Rhodes, Greece. 1600111: International Society of the Learning Sciences; 2009.

6. Lachmann H, Ponzer S, Johansson U-B, Karlgren K. Introducing and adapting a novel method for investigating learning experiences in clinical learning environments. Informatics for Health and Social Care. 2012; 37(3): 125-140.

7. Lachmann H, Ponzer S, Johansson U-B, Benson L, Karlgren K. Capturing students' learning experiences and academic emotions at an interprofessional training ward. Journal of Interprofessional Care. 2012; 27(2):137-145. 8. Lave J. Wenger, E. Situated learning, legitimate peripheral participation. New York: Cambridge University Press; 2009.

9. Morris C, Blaney D. Work-based learning. In: Swanwick, T, editor. Understanding medical education, evidence, theory and practice. London: Wiley-Blackwell; 2010.

10. Siebert S, Mills V, Tuff C. Pedagogy of work-based learning: the role of the learning group. Journal of Workplace Learning. 2009;21(6):443-454.

11. Lewin S, Reeves S. Enacting 'team' and 'teamwork': using Goffman's theory of impression management to illuminate interprofessional practice on hospital wards. Social Science and Medicine. 2011;72(10):1595-1602.

12. Walton JM, Steinert Y. Patterns of interaction during rounds: implications for work-based learning. Medical Education. 2010;44(6):550-558.

13. Jakobsen F, Larsen K, Hansen TB. This is the closest I have come to being compared to a doctor: views of medical students on clinical clerkship in an interprofessional training unit. Medical Teacher. 2010;32(9):e399-406. 14. Hylin U, Nyholm H, Mattiasson AC, Ponzer S. Interprofessional training in clinical practice on a training ward for healthcare students: a two-year follow-up. Journal of Interprofessional Care. 2007;21(3):277-288.

15. Hylin U. Interprofessional education: aspects on learning together on an interprofessional training ward [doctoral degree]. Department of Clinical Science and Education; Stockholm, Sweden: Södersjukhuset, Karolinska Institutet; 2010.

16. Ponzer S, Hylin U, Kusoffsky A, et al. Interprofessional training in the context of clinical practice: goals and students' perceptions on clinical education wards. Medical Education. 2004; 38(7):727-736.

17. Clark P G. Examining the interface between interprofessional practice and education: lessons learned from Norway for promoting teamwork, Journal of Interprofessional Care. 2011:25(1):26-32.

18. World Health Organization. Framework for action on interprofessional education and collaborative practice. 2010 [cited 10 March 2013]; Available from: http://www.who.int/hrh/resources/framework_action/en/.

19. Reeves S, Zwarenstein M, Goldman J, et al. The effectiveness of interprofessional education: key findings from a new systematic review. Journal of Interprofessional Care. 2010; 24(3):230-241.

20. Lidskog M, Löfmark A, Ahlström G. Learning through participating on an interprofessional training ward. Journal of Interprofessional Care. 2009; 23(5): 486-497.

21. Johnson RB, and Onwuegbuzie AJ. Mixed methods research: a research paradigm whose time has come. Educational Researcher. 2004; 33(7):14-26. 22. Csikszentmihalyi M, Larsson R. Validity and reliability of the experience-sampling method. The Journal of Nervous and Mental Disease. 1987; 175(9):526-536.

23. Patton MQ. Qualitative research and evaluation methods. London: Sage Publications; 2002. 
24. Krippendorff K. Content analysis. An introduction to its methodology. London: Sage Publications; 2004.

25. Bazeley P. Qualitative data analysis with NVivo. London: Sage Publications; 2007.

26. Hsieh HF, Shannon SE. Three approaches to qualitative content analysis. Qualitative Health Research. 2005;15(9):1277-1288.

27. D’Amour D, Ferrada-Videla M, Rodriguez LSM, Beaulieu MD. The conceptual basis for interprofessional collaboration: core concepts and theoretical frameworks. Journal of Interprofessional Care. 2005; 19(1):116 -131. 28. Hall P. Professional teamwork: professional cultures as barriers. Journal of Interprofessional Care. 2005;1:188-196.

29. Kvarnström S. Difficulties in collaboration: a critical incident study of interprofessional healthcare teamwork. Journal of Interprofessional Care. 2008; 22(2):191-203

30. Macdonald M, Bally JM, Ferguson LM, Murray BL, Fowler-Kerry SE, Anonson JMS. Knowledge of the professional role of others: a key interpro fessional competency. Nurse Education in Practice. 2010; 10(4):238-242. 31. Nonaka I, Toyama R. The knowledge-creating theory revisited: knowledge creation as a synthesizing process. Knowledge Management Research and Practice. 2003;1:2-10.

32. Paavola S, Hakkarainen K. The knowledge creation metaphor - an emergent epistemological approach to learning. Science and Education. 2005;14(6):537-557.

33. Csikszentmihalyi M, LeFevre J. Optimal experience in work and leisure. Journal of Personality and Social Psychology. 1989;56(5):815-822.

34. Fave A, Massimini F. The investigation of optimal experience and apathy. European Psychologist. 2005;10(4):264-274.

35. O’Daniel M, Rosenstein AH. Chapter 33: professional communication and team collaboration. In: Hughes RG editor. Patient safety and quality: an evidence-based handbook for nurses. Rockville (MD) Agency for Healthcare Research and Quality (US), 2008 [cited 10 March 2013] Available from: http://www.ncbi.nlm.nih.gov/books/NBK2637/. 